\title{
Tradiciones de La Vall d'Uixó Oficios desaparecidos: los espardenyers
}

\author{
Rosario Climent Bueso
}

La Vall d'Uixó ha tenido siempre una larga tradición industrial. Sabemos que, desde tiempos muy remotos, existían en el valle diversas industrias, sobre todo derivadas de la agricultura.

La molinería se mostró pujante en tiempos de los árabes, así como la elaboración del aceite de oliva, el hilado y el tejido para las ropas de uso doméstico; se habla también del alcohol, cuya fabricación tiene sus orígenes en los moriscos, lo que no nos extraña nada dada la abundancia de viñedo que en el término había hasta hace 40 años, cuando

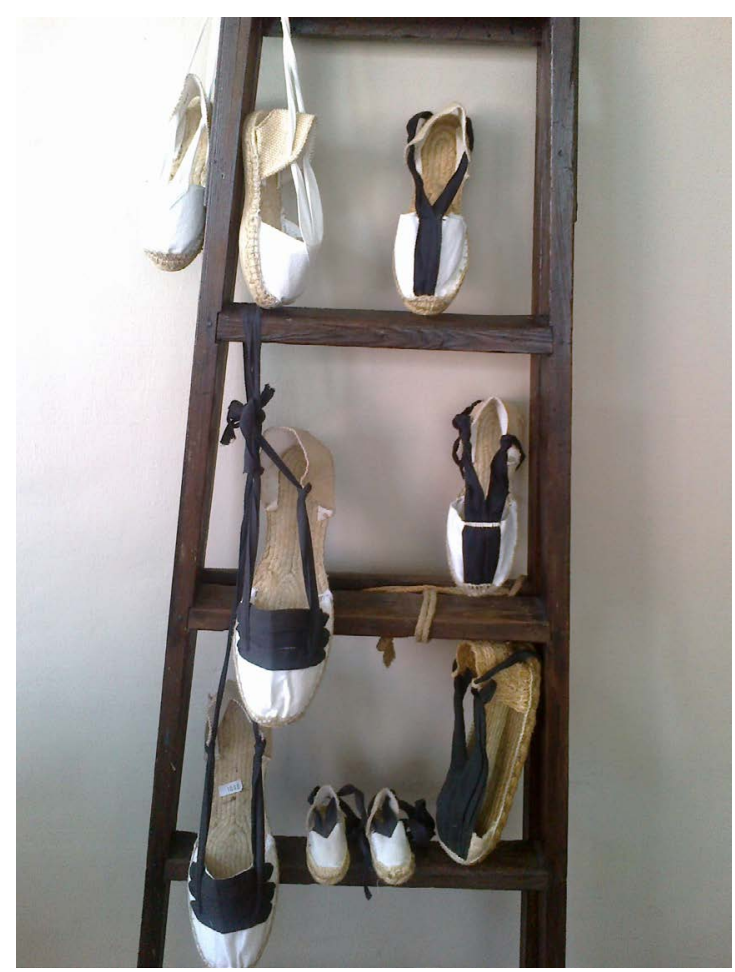

Figura 1. Tipos de alpargatas de antaño aún existían restos de esta industria en los llamados coladores de aguardiente. Pero la industria más importante era la fabricación de la alpargata, cuya aparición se cifra alrededor del año 1610, así como de las industrias subsidiarias de la misma, tales como el hilado, la cestería y la cordelería, que fueron la base de la industria municipal. También tiene gran importancia otra industria tradicional, aunque hoy prácticamente haya desaparecido: se trata de la alfarería, cuyo origen es tan antiguo como el de la alpargata, ya que sabemos que hacia el año 1633 ya había ollers en el valle.

\section{Introducción}

Como consecuencia de un conflicto social, nació la industria alpargatera en La Vall. Siendo todavía

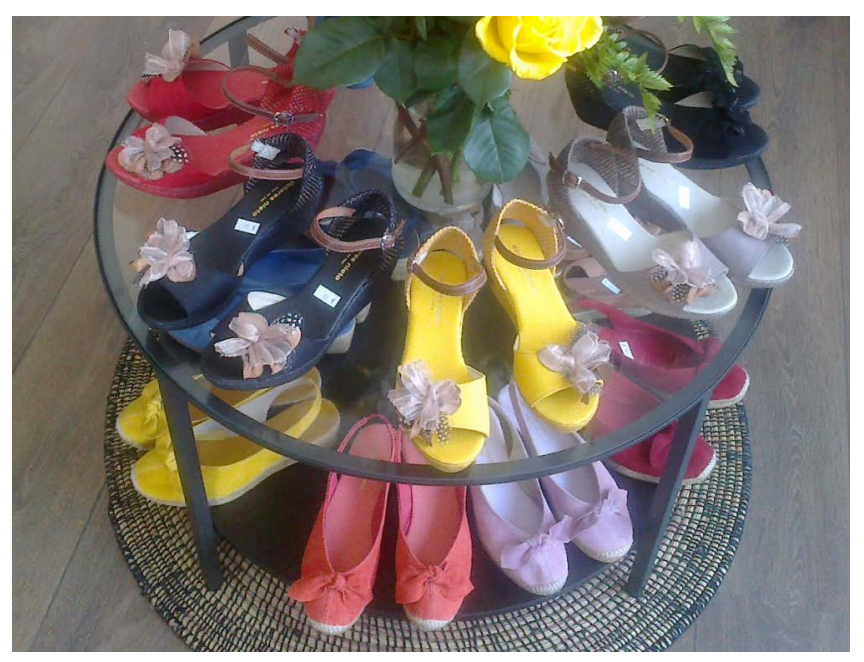

Figura 2. Alpargatas actuales 


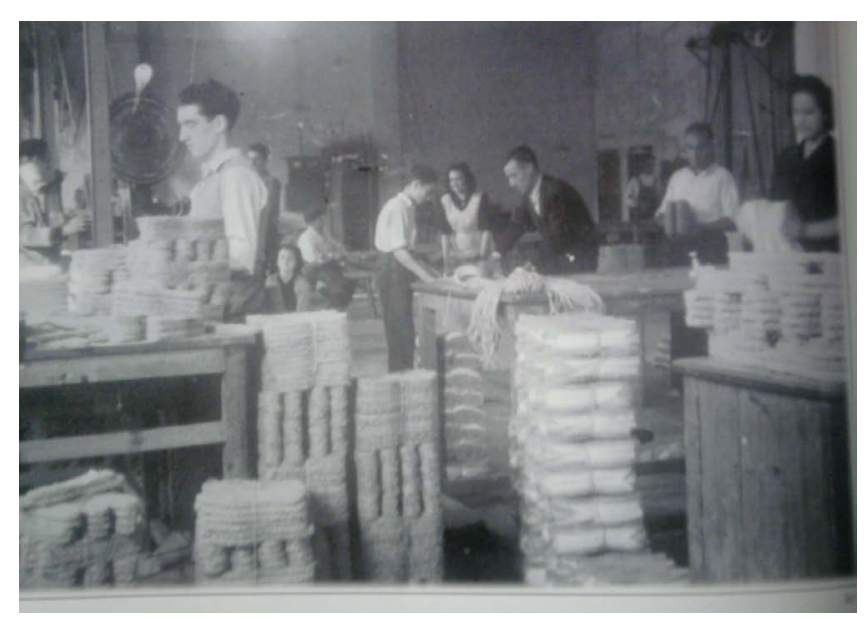

Figura 3. Fábrica de alpargatas, principio del siglo $\mathrm{XX}$

el duque de Medinaceli dueño y señor del valle, surgió una desavenencia entre este y sus colonos a causa de una distinta apreciación en la cantidad a pagar en concepto de arriendo. Los colonos se negaron a pagar la deuda y el duque, para castigar la rebeldía, hizo venir unas familias de Forcall para que cultivaran sus tierras. Ante tal determinación, los colonos depusieron su actitud y volvieron a cultivar la tierra. Pero las familias llegadas del Maestrazgo tuvieron que buscarse una ocupación; como conocían el oficio de alpargatero, empezaron a practicar dicha actividad para cubrir sus propias necesidades, aunque para ello realizaron un trabajo bastante rudimentario y basto.

Es conocido, a través de los archivos municipales, que en el siglo XVIII la riqueza industrial de La Vall d'Uixó en el ramo de la alpargatería que alcanzaba las siguientes cifras:

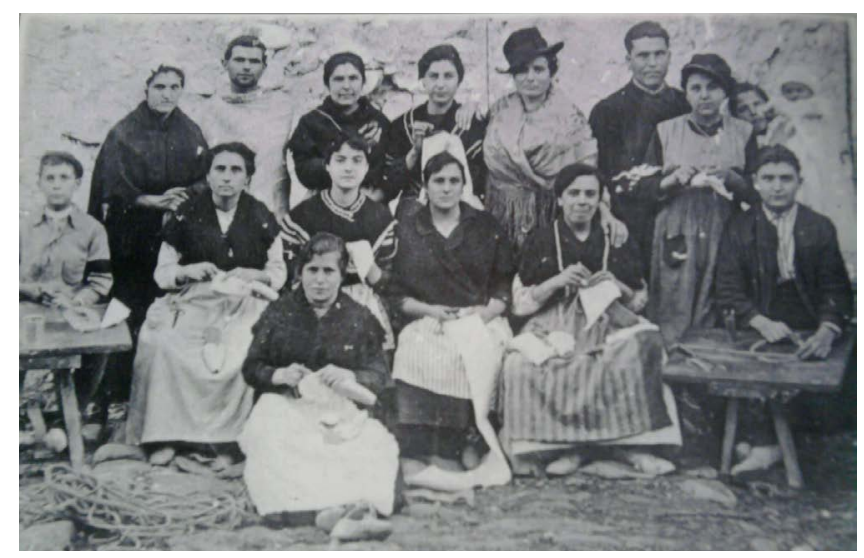

Figura 4. Grupo de espardenyers de principio de siglo
400 alpargateros que fabricaban 800 pares diarios, los vendían de 3 a 4 reales, con un producto de alrededor de 3000 reales diarios. Aparte de estos, había 100 mujeres que se dedicaban a la fabricación de la aixereta para la suela y 15 familias que trabajaban en la confección de otros utensilios.

La aparición de la alpargatería en La Vall d'Uixó, con su consiguiente desarrolló dio lugar a una nueva forma de vida en la ciudad que fue poco a poco tomando auge en la villa e influencia en la vida política de la misma.

A finales del s. XVIII había aumentado ya tanto el número de alpargateros que estos reivindican la participación en la vida pública. Entonces nos encontramos con una época en la que la supremacía de los agricultores no era ya tan clara. A lo largo de varias rencillas, consiguen los alpargateros que se les conceda el derecho a ser nombrados alcaldes de la ciudad, pero solo aquellos que por su poder económico no se viesen obligados a permanecer largas temporadas fuera de la misma por causa de la exportación de la alpargata. En cuanto a esta, la principal zona a la que se exportaba era Cataluña.

La alpargata típica de La Vall era la de careta o cintas, convertida en calzado de campaña en la primera guerra carlista (1833-1840). A partir de entonces, la suerte de la alpargata vallera fue unida

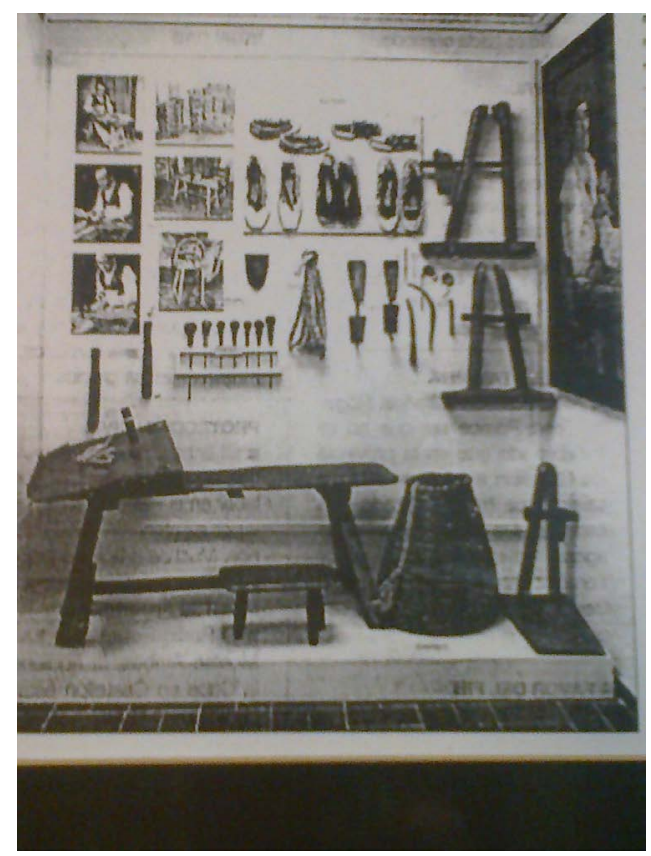

Figura 5. Herramientas para la fabricación de alpargatas 


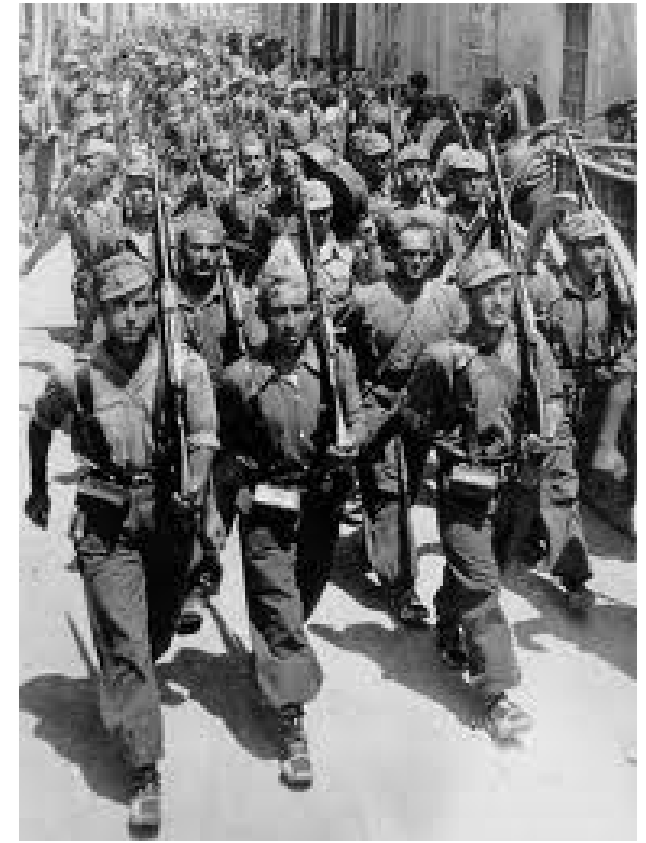

Figura 6. Soldados españoles en Cuba con alpargatas

estrechamente a los altibajos de guerras y paces. De esta faceta artesanal, casi ya desaparecida por completo de nuestra tierras, el Museo Etnológico Provincial muestra, en una de sus salas, la casi totalidad del instrumento básico y preciso para la fabricación de la alpargata.

En la guerra de Cuba de 1895 (figura 6),los soldados españoles usaban traje de rayadillo y calzaban zapatillas tipo catalana, algunas hechas en La Vall d'Uixó. Hay constancia de que algunos valleros se trasladaron a Cuba para confeccionar allí las alpargatas, llevándose los bancos de ordir y todos los materiales y utensilios para confeccionarlas.

Entre los años 1921 y 1925, D. Silvestre Segarra era proveedor de las alpargatas que llevaban en Marruecos los soldados españoles. Esta época fue muy próspera para la industria alpargatera de La Vall.

A partir de la guerra civil, el número de fabricantes disminuyó debido al gran desarrollo que alcanzó la fabricación del calzado. Solo quedaban 12 industrias de alpargateros, formando un gremio industrial reconocido por el Estado, de las 87 que existían a principios de siglo.

La fabricación de la alpargata ha tenido dos variaciones: de esparto y de cáñamo.

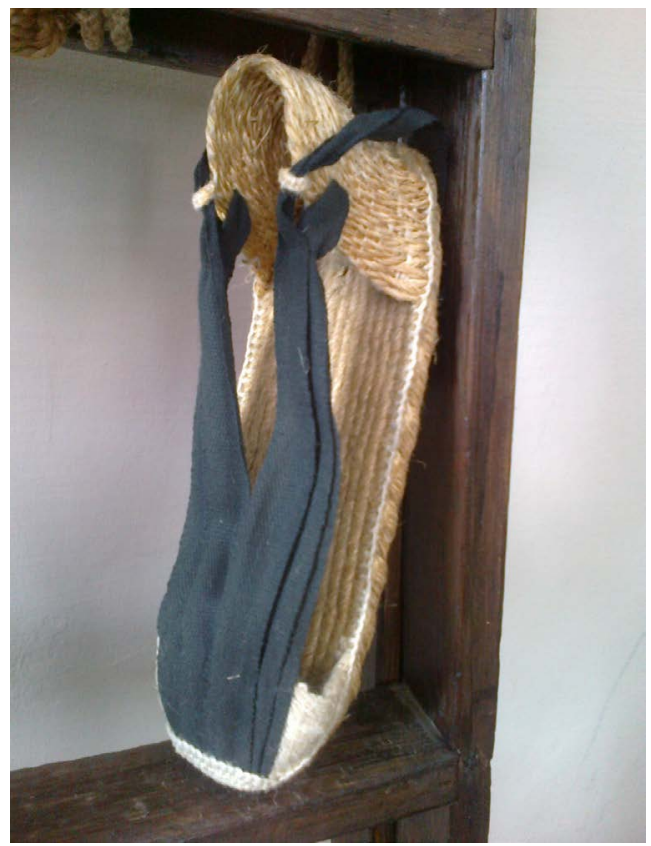

Figura 7. Modelo de alpargata usada por soldados españoles en Cuba

\section{Alpargata de esparto}

Existía, según D. Vicente Traver, persona culta y dedicada a la investigación de temas históricos, lo que él llama la «ruta del esparto». Esto consiste en que, según sus afirmaciones, podemos localizar la formación del esparto virgen desde More-

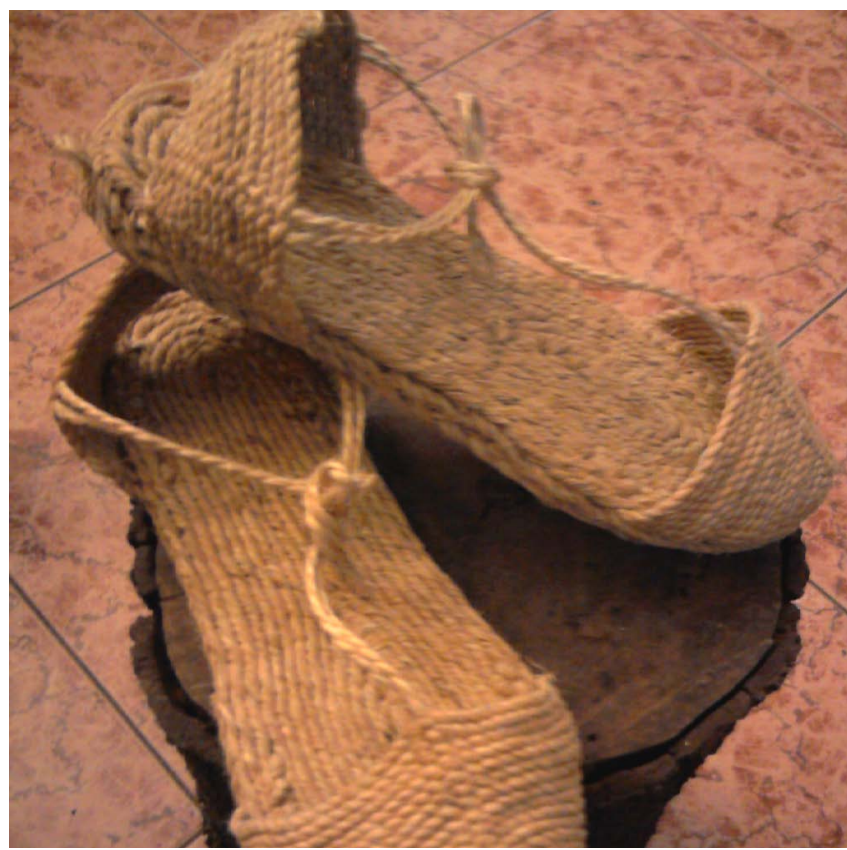

Figura 8. Alpargata de esparto puro y suela de carreter 


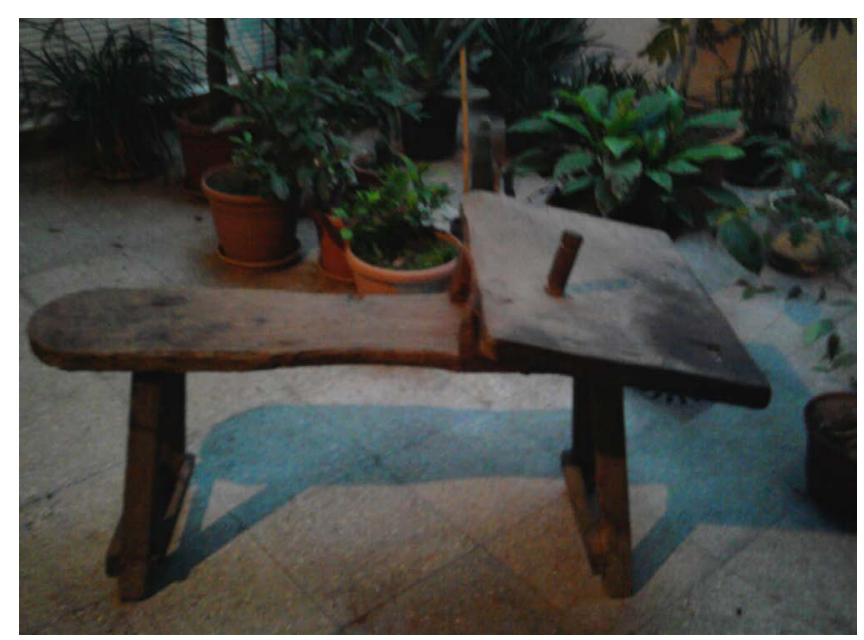

Figura 9. Barco de ordir

lla hasta las proximidades de Xàtiva, pasando por La Vilavella, La Vall d'Uixó y Cheste.

Él añade a esta afirmación que la zona costera de La Vilavella y La Vall d'Uixó siempre ha tenido un esparto más dorado y resistente debido a la influencia del aire marino. Todo esto podía dar lugar a una localización de la industria alpargatera del esparto en La Vall d'Uixó. Pero nosotros añadimos a esta hipótesis de la aparición de tal industria en nuestra ciudad a la circunstancia de que ha sido un producto de la clase campesina, que lo utilizó no solo para la fabricación de calzado sino también en la de capazos y utensilios propios para la labor de la tierra. Esto se ve confirmado por el hecho de que la industria del esparto está localizada en la zona agrícola de la ciudad.

\section{Fabricación de la alpargata de esparto}

El esparto se pone a remojo unos días, según el calor. Después, se tiende al sol y, cuando está bien seco, se pica con un mazo de madera, colocando el esparto sobre una gran piedra. Esta operación se realiza para sacar las fibras bien finas con las que se hace la cuerda para las suelas.

La cuerda suele hacerse de tres cabos. Una vez terminada, se comienza la fabricación mediante la operación de ordir, que es hacer la suela. Para ordir se toma un trozo tan grande de cuerda como grande queramos hacer la suela.

La operación de cortar la cuerda según el tamaño que vaya a tener la alpargata se llama tallar.

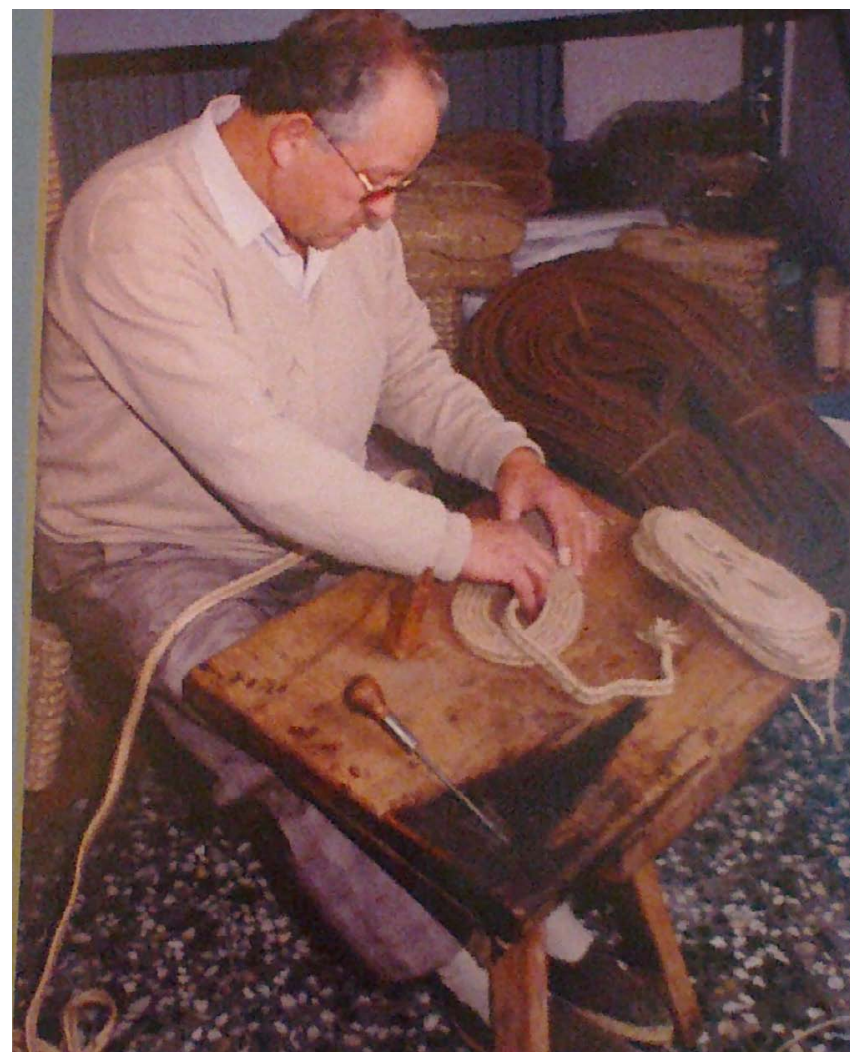

Figura 10. Proceso de hacer suela ordir Faustino nieto

La cuerda se va enrollando en forma de espiral; empezando por fuera, se coge mediante un cordón para que no se deshaga la labor realizada hasta llegar al centro. En la parte delantera, se recogen las últimas vueltas.

Realizada la operación de confección de la suela, se cose esta utilizando un hilo de esparto llamado nyinyol, valiéndose de una aguja especial que consta de un mango de madera y un largo punzón.

Terminada la suela, se procede a encordar, que consiste este trabajo en realizar la cara delantera. Se utiliza para ello un hilo de esparto hecho a mano, el cual se bruñe bien para que esté fino y brillante.

El trabajo de encordar lo hacen las mujeres con una aguja larga de $22 \mathrm{~cm}$ y, para ello, se ponen un caballet de madera junto a la suela. Se pasa la aguja con el hilo y se va cosiendo de una parte a otra del empeine hasta unas 23 o 24 vueltas. El caballet es el que hace la horma de la cara

El talón se hace del mismo modo, pero usando una talonera de hierro. El cordell de detrás, de la talone- 


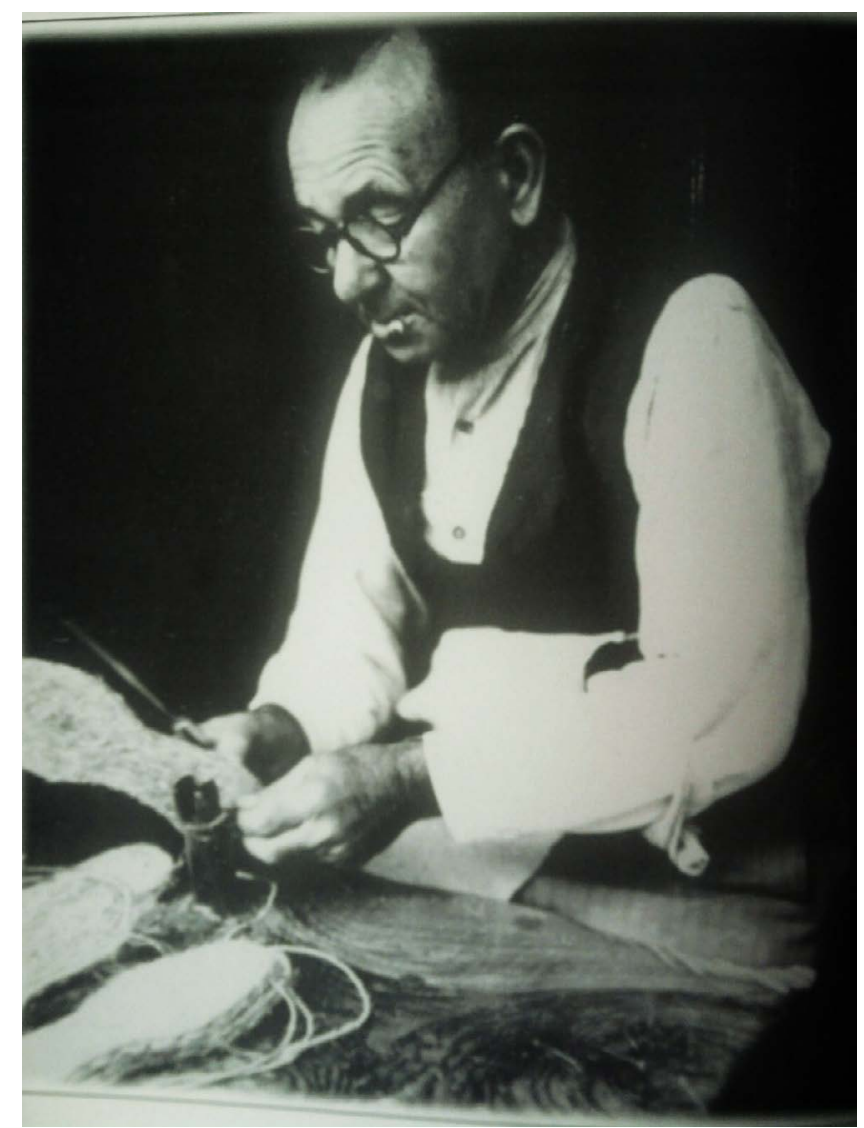

Figura 11. El tio Andrés, cosidor

ra, es más gordo y menos brillante, dando unas 14 o 16 vueltas para terminar la misma.

Una vez hecho el talón y la cara, se pasa un cordel de cáñamo a través de los cordeles del talón, por la parte de la derecha y en dirección de atrás a delante; se da la vuelta metiéndolo otra vez muy junto al otro, dejando un trozo fuera para atarse. Se mete la aguja por la parte del talón, se saca y se vuelve

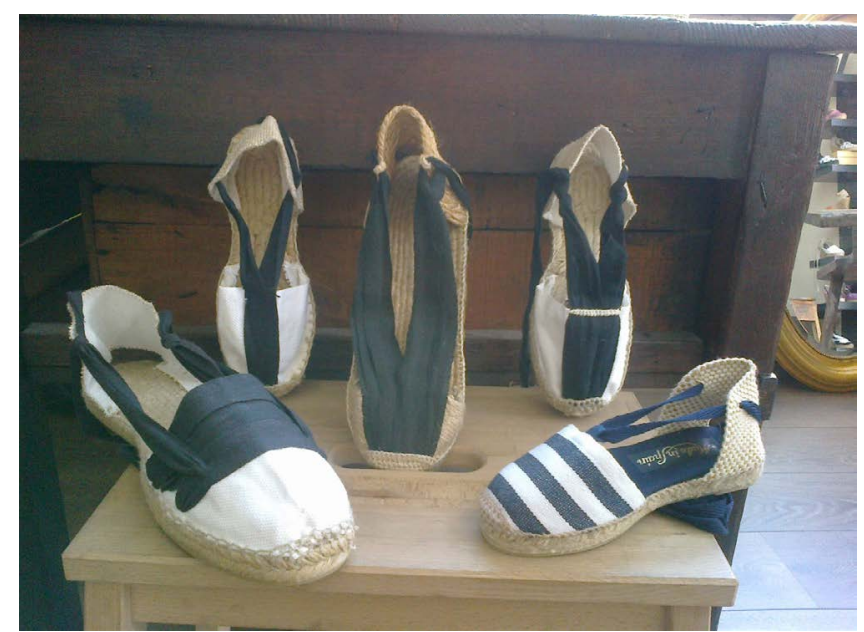

Figura 12. Variedad de alpargatas de esparto

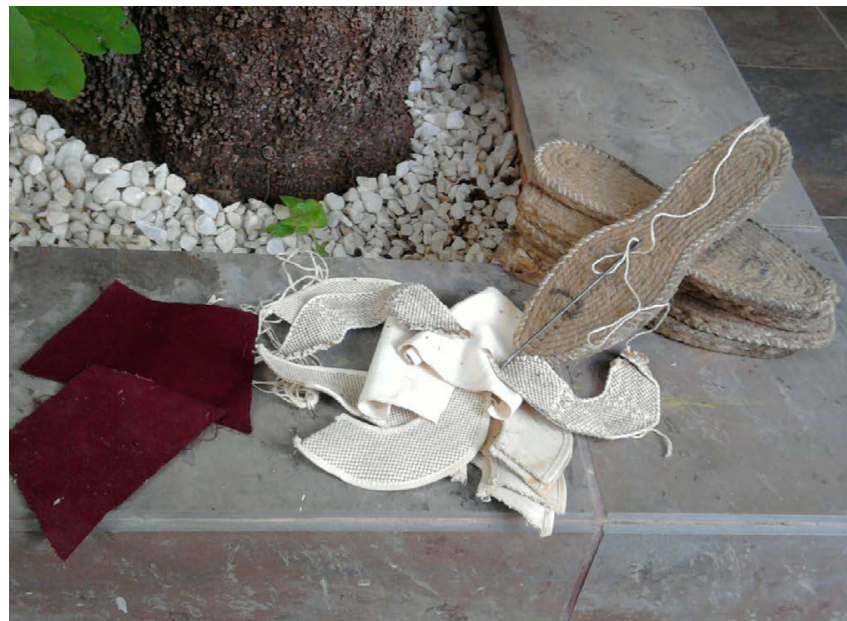

Figura 13. Material para fabricar alpargatas

a meter por el mismo sitio pero hacia atrás. Otra vez se mete por el talón, en su parte izquierda, y se lleva el extremo a la cara de la alpargata atravesándola por el centro y volviendo a pasar el hilo hacia atrás. Se mete de nuevo en el talón por la parte izquierda y, así este cordel sirve para sujetar la alpargata al pie y el otro extremo que quedó suelto se ata al otro sobre el empeine.

El precio de esta alpargata era de 40 pesetas y el kilo de esparto valía 15, o sea que se ganaban unas 25 pesetas; esto teniendo en cuenta que un par de alpargatas costaba más de dos horas de hacer.

Actualmente ya no se fabrica este tipo de alpargata en su tipo puro, es decir, toda de esparto. Algunas personas que fabrican este tipo de calzado lo hacen pegándole a la suela otra de goma para que resulte más resistente; la talonera y la cara son de cáñamo y reciben el nombre de albarcas.

\section{Alpargata de cáñamo}

\section{Fabricación de la alpargata de cáñamo}

Ha habido muchos modos de hacer la alpargata de cáñamo. Hace más de 200 años se usaba para hacerlas una trenza de cáñamo. Después, se utilizó la trenza de yute.

La primera trenza de yute que apareció se llamaba sin ànima (sin alma) porque era totalmente hecha con esta fibra. Luego se ha empleado yute en ànima (en alma) porque lleva una fibra interna que hace que la trenza se mantenga tiesa. Existe también la 


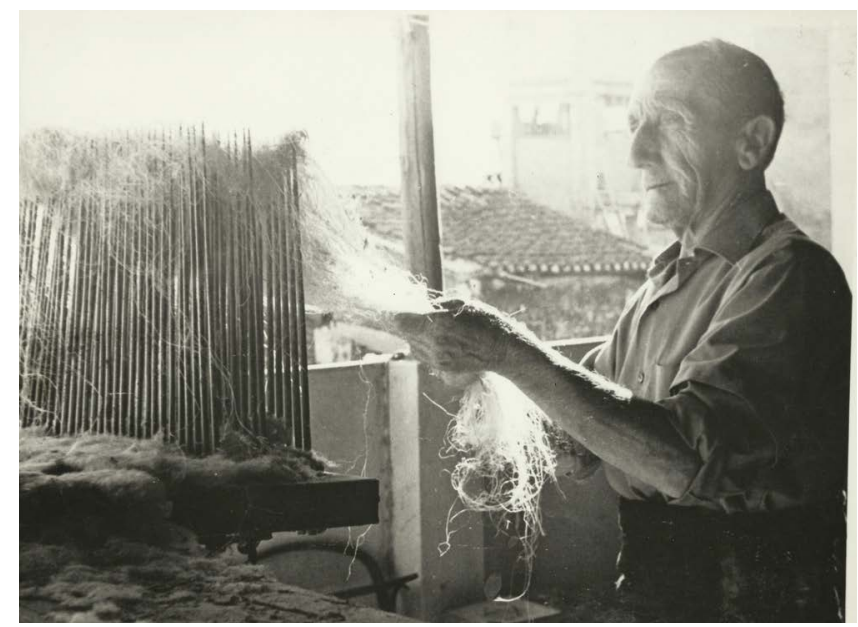

Figura 13. El tipo Pepe Llor, pentinaor

trenza de esparto, cuya utilización fue posterior a las citadas. Finalmente, la que mas uso ha tenido ha sido la trenza llamada encapada, que es también de esparto pero lleva una cobertura de cáñamo.

La procedencia del cáñamo con el que se fabricaba la alpargata ha sido fundamentalmente de $\mathrm{Ca}$ llosa del Segura, Lleida y Bolonia. La procedencia del yute ha sido siempre de origen extranjero, Portugal y la India preferentemente.

La guita es la labor de sujeción de la alpargata. Ha sido realizado siempre este trabajo de confección por las tancaores. El hilo que se utiliza para coser las suelas se llama cosedera y es el más fino que resulta del trabajo del filaor.

La guita es el hilo que tiene importancia fundamental en el cosido de la alpargata. Ha sido realizado siempre este trabajo de su confección por los filaors. La cuerda que está formada por más de una guita se llama cosedera y se utilizaba para coser las suelas.

La aixereta se confecciona con los hilos de la mocà una vez realizada la operación de pentinat; a la persona que realiza este trabajo se le llama pentinaor.

La gireta o treneta es una trenza fina de 3 o 4 hilos que sirve para rematar las alpargatas de señora $y$, al mismo tiempo, sujeta el corte a la suela. Se solía hacer de 4 o 5 colores según fuera el color del corte de la alpargata.

Con la trenza de cáñamo llamada aixereta se realizan las siguientes operaciones para formar la al-

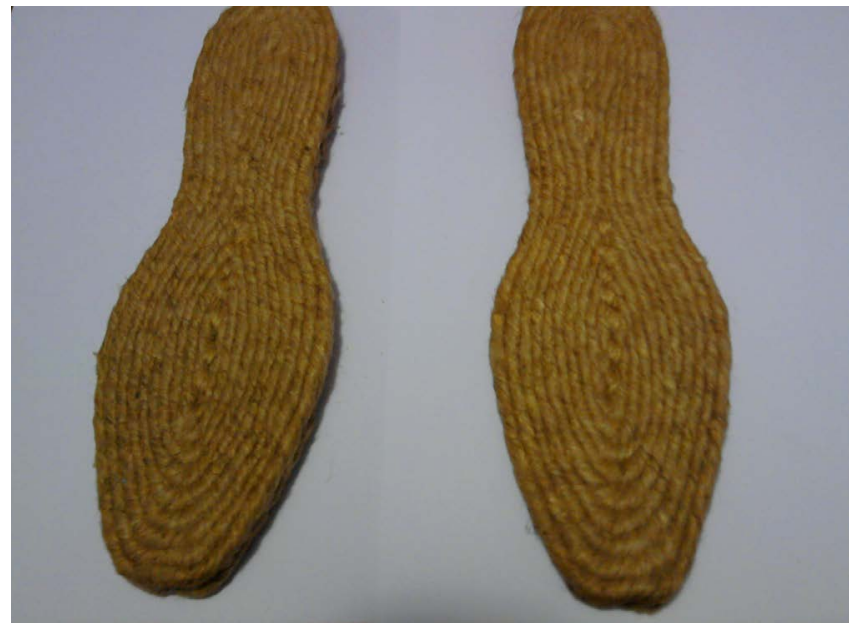

Figura 14. Suela de hechura

pargata; esto se hace en cadena, nunca una persona sola realiza todas las operaciones. Así, podemos encontrar los especialistas siguientes: aixeretera, ordidor, cosidor, plantillaor, tancaora, ensintaora y embalaora.

Ordir es hacer la suela. Esta se hace en un banco de madera especial y el proceso es semejante al que ya hemos visto al hablar de la alpargata de esparto. Después de ordir, se procede a coser la suela, también en el banco. Esta operación la hace el mismo ordidor mediante una aguja especial con mango

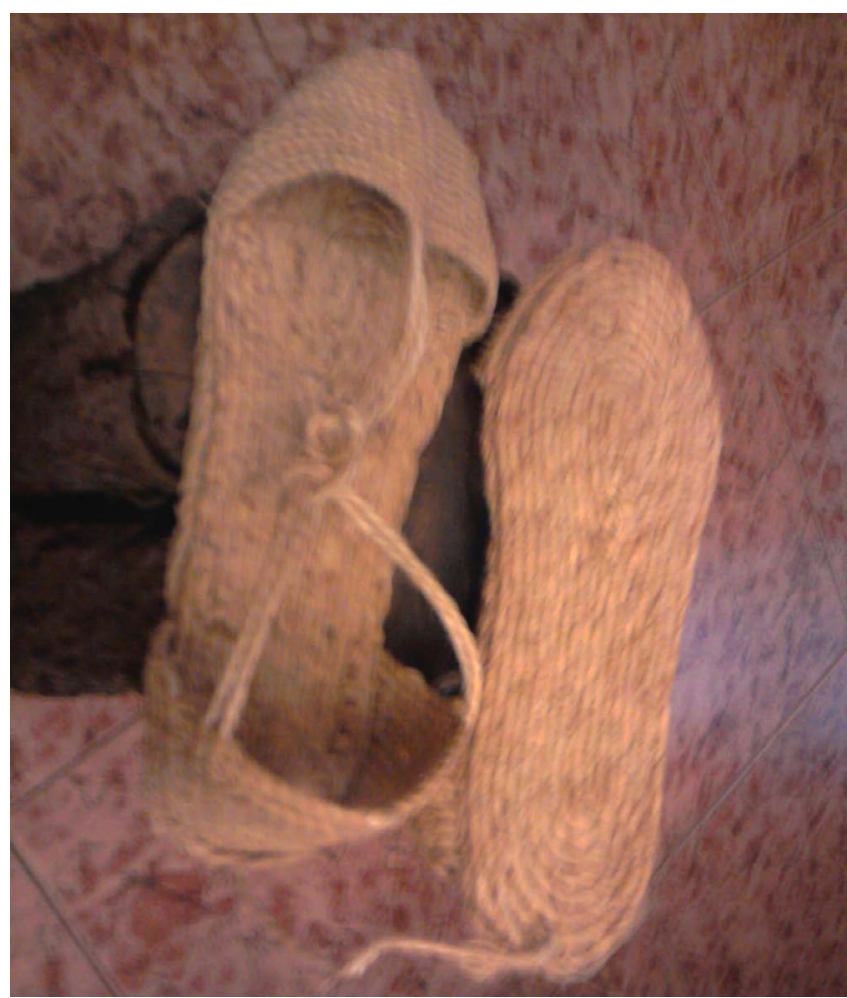

Figura 15. Suela de carreter 


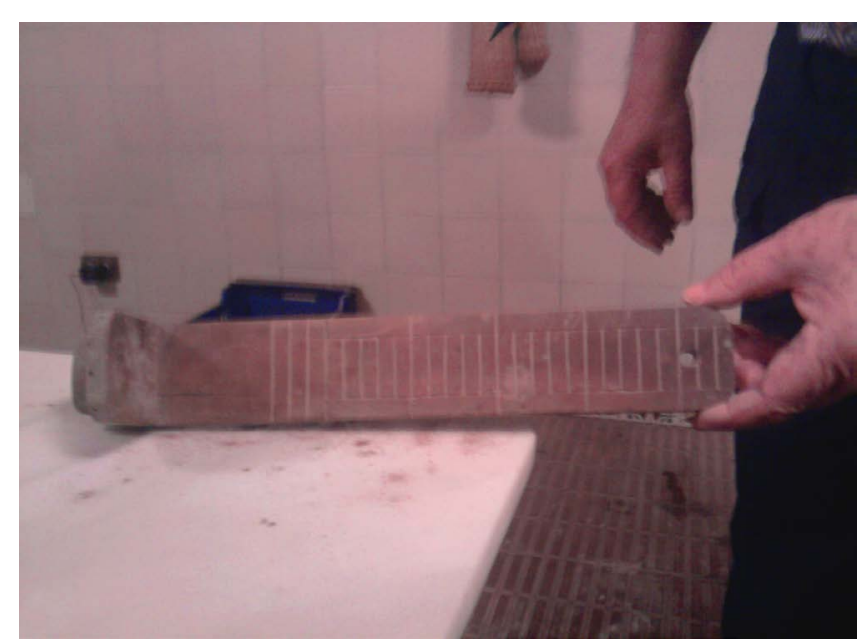

Figura 16. Paleta

de madera. Se cose enhebrando y desenhebrando cada vez que se pasa la aguja de un lado a otro. Posteriormente, esta operación se podía realizar a máquina gracias a dos tipos de máquinas: máquina plana, inventada por Larramendi, y máquina vertical de Larrañaga.

Mediante el cosido se pueden hacer varios tipos de suela.

- De plantilla: que tiene forma para el pie derecho y el izquierdo.

- De hechura: con igual forma para el pie izquierdo que el derecho.

- De carreter: sin forma.

Después de cosida la suela, se mide y se numera. La medida se realiza mediante la paleta, un instrumento de madera que tiene doble numeración, en centímetros y en números (figura 16).

Durante la plantillación, se realiza la operación de la colocación de la lona del talón y la cara.

Después, se realiza la operación de tancar, que consiste en hacer un festón al borde de la suela para que quede bien cerrada. En la parte inferior, en vez de festón se hace un bordó. Esto cuando el trabajo es sin horma. Cuando se le da horma a la plantilla, la plantillaora es la misma que hace la operación de cerrado o tancat.

La zapatilla con horma requiere una técnica distinta: cortar la lona, trabajo hecho por la tallaora, repuntar las piezas por parte de la repuntaora y, si se quiere bordado, lo hace la bordaora. Si el modelo

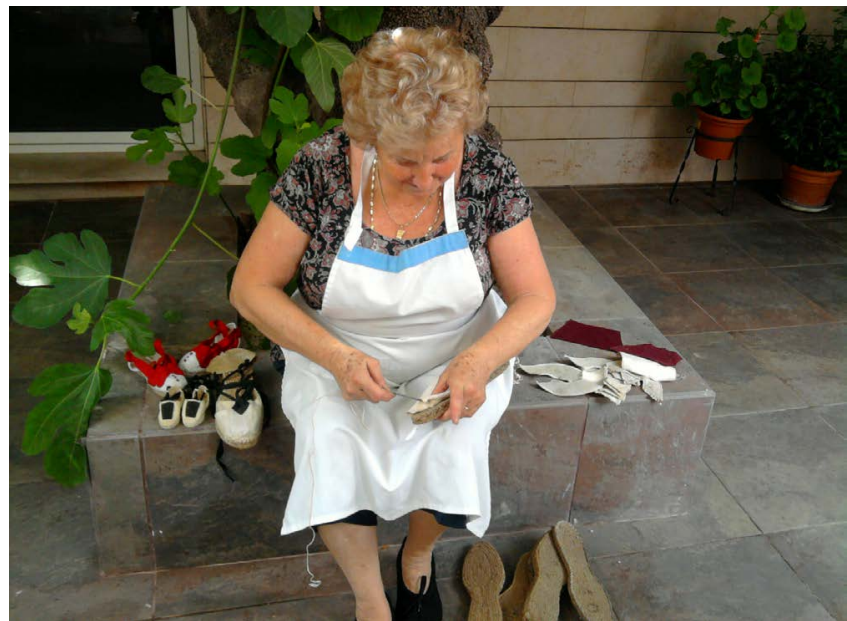

Figura 17. Vicentica Aragó, tancaora, encaraora, bordaora, repuntaora. Hija del tío Pepe espardenyer

de la zapatilla lo requiere, se colocan cintas para atarla a los pies, trabajo que hace la encintadora.

Modelos más comunes de alpargatas:

- Carreter: alpargata con cintas negras. Catalana: alpargata con suela de carreter cubierta de cinta negra.

- Barcelonesa: con guita y media.

- De gometa: lleva una goma en el empeine.

- Inglesa: abierta con ojales.

- Salón: corte cerrado delante y detrás. En las de señora, la sujeción del corte a la suela es por mediación de la treneta.

- Chinela: destalonada.

- Copete: la cara tiene forma de triángulo o pico.

- Cangrejo: con la lona girada.

- Guitarró o de careta: con cintas negras y cosidas en la cara.

- Valenciana: es igual que la catalana pero con veta blanca y con la talonera y puntera reforzada.

- Bota: es como la bota de cuero pero con trabajo de lona.

- Topolino: alpargata de señora con un pequeño alce en la suela situado en la talonera.

- Pascuera: alpargata que como el nombre lo indica, se estrenaba en Pascua. Llevaba un pequeño tacón de madera y en la careta iban bordados algunos motivos florales.

En la actualidad, quedan muy pocas fábricas de alpargatas y estas son muy distintas a las que había 


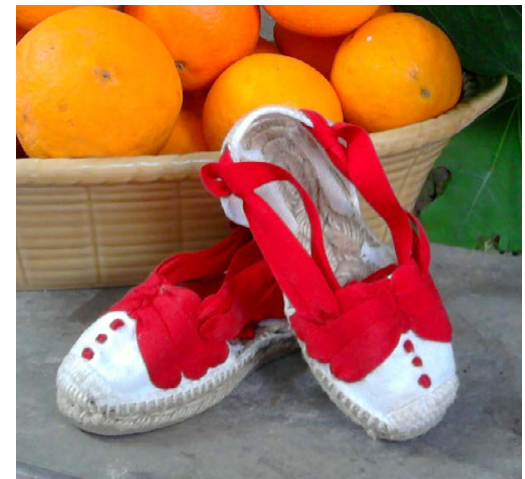

Figura 18. Alpargata valenciana de tipo paloma

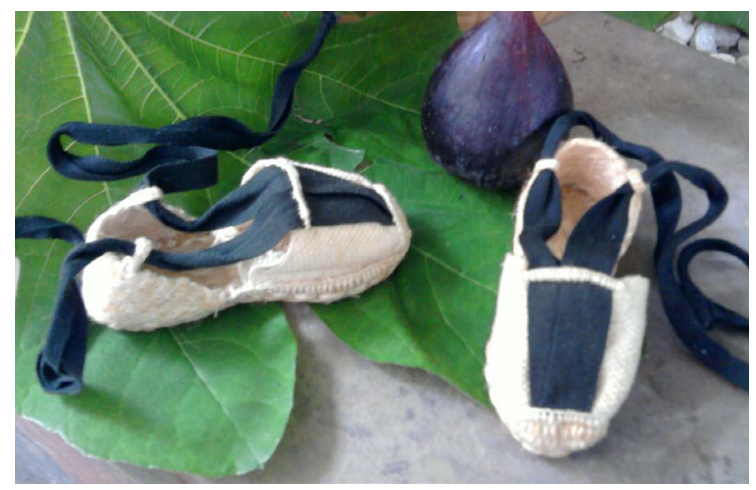

Figura 19. Alpargata de cáñamo tipo militar

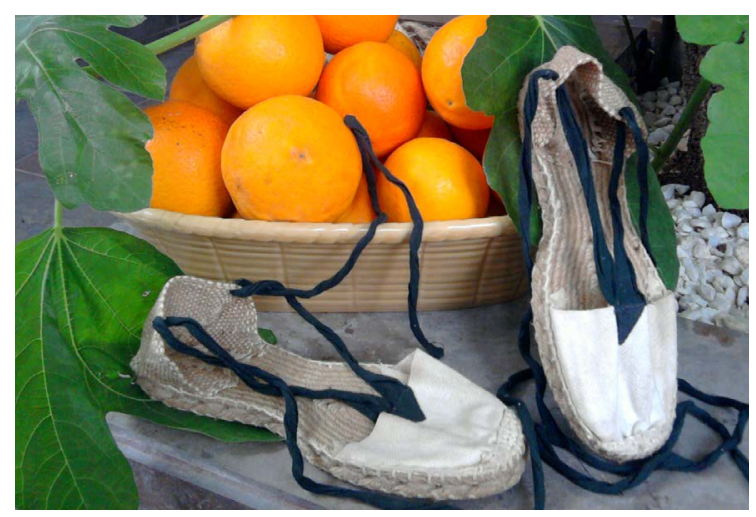

Figura 20. Alpargata de guitarró o careta antiguamente. Los bancos de ordir y las funciones que realizaban las personas han sido sustituidas por las máquinas, así como los materiales y el estilo de las zapatillas.

\section{Conclusiones}

Cuando el diseño es tan perfecto como el de la alpargata tradicional, a los creadores de moda no les queda otro remedio que dar vuelta sobre el mismo tema: de los labradores a los artistas del exilio; de los artistas a los primeros hippies; de los hippies a los exquisitos poseedores de refugios ibicencos. Y de ahí a la moda internacional y, paralelamente, a la moda de consumo de masas; del consumo masivo a las alpargatas de firma.

Ahora, a principio del s. XxI, la alpargata se hace de nuevo un lifting y se pone a la vanguardia y todo esto sin despegar los pies del suelo.

\section{Referencias}

Este trabajo es una recopilación de datos extraídos de un trabajo de investigación sobre La Vall D’Uixó realizada por D. Rafael Solá Llorca, catedrático de Historia del cei de Cheste. En su día entrevistó a Vicente Moliner, espardenyer, al tío Pepe Aragó, espardenyer, y a algunos espardenyers más.

Fuentes orales:

Entrevista oral: D. Vicente Peirats Aragó, hijo de D. Vicente Peirats Montón, espadenyer; a D. Faustino Nieto Alcázar, espadenyer; Dña. Vicenta Aragó Diago, hija de D. José Aragó Moliner, espardenyer.

Material cedido por: Dña. Vicentica Aragó, D. Julio Palomo, D. Vicente Peirats, Dña. Fina Marrama, D. Joaquin Fenollosa (Manzano). Fábrica de alpargatas. Dolores Nieto (hija del antiguo espadenyer Faustino Nieto).

Fotografías: Rosario Climent Bueso.

Observación antropológica: Rosario Climent Bueso. 